\title{
Conceitos, modelos e novas perspectivas de avaliação em Arquivologia e Ciência da informação
}

\author{
Moisés Rockembach \\ Doutor; Universidade Federal do Rio Grande do Sul (UFGRS), Porto Alegre, RS, Brasil; \\ moises.rockembach@gmail.com
}

\begin{abstract}
Resumo: O trabalho apresenta o processo de avaliação da informação a partir de uma análise das metodologias propostas por diferentes autores no campo da Arquivologia e da Ciência da Informação. Este estudo parte de uma perspectiva clássica da avaliação, com Jenkinson (1922) e Schellenberg (2003), mediante seu conceito de valor de documento; uma abordagem pós-moderna de macroavaliação proposta por Terry Cook (2005), que critica o modelo anterior e propõe uma abordagem sistemática e holística do processo; até a interdisciplinaridade com a Ciência da Informação em Silva e Ribeiro (2000; 2004); e Ribeiro (2005) com o estudo dos fluxos informacionais. Propõem-se perspectivas complementares do valor da informação, com os conceitos de indício, evidência e prova (ROCKEMBACH, 2012, 2013a, 2013b, 2013c), e, ainda, a Teoria dos Atos dos Documentos (SMITH, 2005). Traz como considerações finais a importância que o debate interdisciplinar pode ter na construção terminológica e metodológica sobre avaliação.
\end{abstract}

Palavras-chave: Avaliação da informação. Modelos de avaliação. Arquivologia. Ciência da informação.

\section{Introdução}

O presente estudo ${ }^{1}$ pretende debater como o processo de avaliação da informação vem sendo modificado ao longo do tempo, comparando metodologias de diferentes autores, desde uma perspectiva arquivística clássica (JENKINSON, 1922; SCHELLENBERG, 2003), uma abordagem pós-moderna de macroavaliação (COOK, 2005), até a interdisciplinaridade com a Ciência da Informação (RIBEIRO; SILVA, 2000, 2004; RIBEIRO, 2005).

O estudo dos usos da informação enquanto caráter informativo, evidencial e/ou probatório tem papel central em nossa pesquisa e, para isto, é fundamental o entendimento da relação entre aquele que produz a informação e aque- 
le que a utiliza, podendo por vezes significar uma diferença na intencionalidade dos sujeitos.

Portanto, outra linha que pode ancorar modelos de avaliação da informação fixa-se na Teoria dos Atos dos Documentos (SMITH, 2005), uma perspectiva advinda da Filosofia da Linguagem e da Teoria dos Atos da Fala (SEARLE, 1995), que, além dos usos informativos e probatórios, aborda as esferas ética, legal, social e institucional dos documentos, trazendo um complemento no estudo avaliativo da informação. Ademais, o modelo da evidência da informação (ROCKEMBACH, 2012, 2013a, 2013b, 2013c) propõe-se a diferenciar a informação enquanto indício, evidência e prova e também como a informação pode ser representada em níveis de evidência.

Utiliza-se de metodologia qualitativa, com revisão bibliográfica, pesquisa teórica e estudo comparativo conceitual e sistêmico dos modelos de avaliação da informação. Entende-se que a mudança de paradigmas da informação e a introdução das tecnologias e das interações complexas dos sujeitos na produção, usos e fluxos da informação, resignificam o processo avaliativo, que nasceu da necessidade de racionalização física dos documentos e dos usos para a pesquisa histórica, e migra para uma análise dos fluxos informacionais e uma construção epistêmica da memória da sociedade.

\section{Perspectivas clássicas sobre avaliação: Jenkinson e Schellenberg}

O paradigma custodial e sincrético (SILVA et al., 1998) foi demarcado pela Revolução Francesa, que trouxe mudanças na organização e guarda dos documentos a partir de uma institucionalização do local de custódia (Arquivo Nacional Francês), armazenando a identidade do Estado-Nação e servindo de fonte para a História. Na mudança para o paradigma custodial e técnico, temos pela primeira vez uma manualização do saber e fazer arquivístico, representado pelo Manual dos Arquivistas Holandeses de 1898 (MULLER; FEITH; FRUIN, 1973). Neste paradigma há uma vinculação da Arquivologia com a Administração, de forma que os documentos são pensados em termos de usos administrati- 
vos e históricos. Proveio disto, inclusive, a separação dos profissionais entre "records managers", os administradores de documentos, e "archivists", os arquivistas históricos (SILVA et al., 1998), posições que posteriormente convergiram a partir da arquivística integrada (ROUSSEAU; COUTURE, 1998). Surge a preocupação em racionalizar os documentos em razão dos espaços físicos de guarda, mantendo aqueles que terão maior importância informativa ou histórica.

O britânico Hilary Jenkinson, que com seu Manual de Administração de Arquivos destacava o caráter único, autêntico e imparcial dos arquivos, ligados ao valor de prova dos documentos (JENKINSON, 1922), também demarca este paradigma, assim como o norte-americano Theodore Roosevelt Schellenberg, na década de 1950, com sua visão de administração de arquivos modernos e seus conceitos de valor da documentação, primário e secundário ${ }^{2}$ (SCHELLENBERG, 2003).

Entretanto, há algumas diferenças entre as abordagens de Jenkinson e Schellenberg, já destacados por exemplo, por Tschan (2002) notadamente as críticas de Schellenberg sobre o trabalho de Jenkinson no que concerne a aplicação prática de critérios de avaliação e eliminação e em uma necessidade de melhorar a eficiência governamental. Schellenberg, além do mais,

[...] acreditava em uma aplicabilidade limitada das práticas de arquivo européias para as realidades da produção de arquivos modernos nos Estados Unidos, entendendo que deveria haver uma nova concepção de administração de arquivos. ${ }^{3}$ (TSCHAN, 2002, p. 179, tradução nossa).

Outro ponto a ressaltar são os contextos históricos no surgimento das obras de ambos os autores, que indicam algumas das suas preocupações. Jenkinson (1922) publica seu manual no período pós $1^{\text {a }}$ Guerra Mundial, com crescimento da burocracia moderna e de sua documentação. Ainda questionava sobre a falta de centralização dos arquivos ('central registry') como forma de descontrole sobre os documentos.

Já Schellenberg teve como contexto um ambiente com maior uso de tecnologias e maior produção científica, que aumentam a produção de documentos em papel. Ainda sobressaltam os enfoques em procurar solucionar problemas relativos ao custo do espaço físico (armazenamento da documentação) e dificuldade na recuperação da informação. 
Os valores primário e secundário trazidos por Schellenberg formaram a base da avaliação em muitas instituições em todo mundo. Rousseau e Couture (1998) recuperam estes conceitos propostos por Schellenberg, originalmente em 1956, que influenciaram gerações de arquivistas, indicando o valor primário como a qualidade relacionada aos usos imediatos e administrativos dos produtores das informações registradas (ROUSSEAU; COUTURE, 1998), enquanto que o valor secundário "[...] define-se como sendo a qualidade do documento baseada nas utilizações não imediatas ou científicas. Essa qualidade radica essencialmente no testemunho privilegiado ou objetivo que o documento fornece." (ROUSSEAU; COUTURE, 1998, p. 117).

Para além dos já consagrados valores primários e secundários dos documentos, torna-se necessário realizar a busca dos modelos de avaliação que surgiram posteriormente. Makhlouf e Cavalcante (2008) fazem uma revisão de literatura sobre avaliação arquivística a partir de cinco autores considerados essenciais no entendimento do tema: Booms, com o plano documental (1970, 1972, 2002), Samuels, com a estratégia documentária (1986), Cook, com a macroavaliação (1992, 1994, 1997, 1999, 2005), Eastwood, com a micro-avaliação (1992, 2002), e Couture, com a avaliação integrada (1998, 1999, 2002). Destes, vamos destacar o modelo de Terry Cook, com sua macroavaliação, e acrescentaremos o estudo dos fluxos informacionais, de Silva e Ribeiro (2000 e 2004) e Ribeiro (2005), que demarcam a convergência das metodologias de avaliação para uma perspectiva pós-moderna e científica sobre a informação.

\section{A macroavaliação de Cook e uma abordagem da ciência da informação a partir de Silva e Ribeiro}

A macroavaliação como metodologia avaliativa é utilizada, por exemplo, nos Arquivos Nacionais do Canadá (país de onde esta metodologia tem origem, a partir das propostas de Terry Cook), Holanda (por meio do projeto PIVOT), Austrália e África do Sul. Ela surge da crítica ao modelo pragmático posto por Schellenberg, que, ao invés de utilizar de uma teoria de valores (primário e se- 
cundário), possui uma abordagem sistemática e holística, adotando um grande quadro (big picture) e uma avaliação de cima para baixo (top down) (CUNNINGHAM, OSWALD, 2005). É levado em conta, principalmente, o contexto de criação do documento e o enfoque se dá nas funções das instituições produtoras destes documentos.

Cook desenvolveu sua metodologia macroavaliativa por meio dos estudos Records and Archives Management Programme (RAMP) no Conseil International des Archives (CIA) entre 1989 e 1990. Esta macroavaliação avalia o valor da sociedade tanto do contexto funcional-estrutural quanto da cultura local de trabalho em que os documentos são criados e usados por seu(s) criador(es), e a inter-relação dos cidadãos, grupos, organizações - "o público" - neste contexto funcional-estrutural (COOK, 2005).

A maneira como é realizado o processo macroavaliativo, segundo Cook (2005) deve acontecer de forma clara, metodologia que se inicia desde a pesquisa das funções, subfunções e programas realizados pela instituição; do local onde são exercidas estas atividades; das expressões mais utilizadas pelos cidadãos que interagem com estas funções/programas; da elaboração de uma hipótese de macroavaliação e, por fim, o teste e confirmação desta hipótese.

Já sob um prisma de uma Ciência da Informação inter e transdiciplinar, torna-se necessário primeiramente o entendimento de qual objeto estamos tratando e qual o seu significado: o que é a informação? Dentre os diversos conceitos atribuídos, elencamos o que consideramos o mais pertinente neste contexto:

[...] conjunto estruturado de representações mentais codificadas (símbolos significantes) socialmente contextualizadas e passíveis de serem registadas num qualquer suporte material (papel, filme, banda magnética, disco compacto, etc.) e, portanto, comunicadas de forma assíncrona e multi-direcionada. (SILVA, 2006, p. 150).

Neste viés, analisamos a metodologia de avaliação sobre o fluxo informacional (RIBEIRO; SILVA, 2000, 2004; RIBEIRO, 2005). Os autores recorrem ao uso do método científico para o tratamento desta temática - a avaliação e, dentre os métodos científicos, definem o Método Quadripolar (BRUYNE; HERMAN; SCHOUTHEETE, 1977) como o mais adequado. 
Esta avaliação pode acontecer em diversas dimensões - os desempenhos dos serviços de informação, a eficácia e eficiência da recuperação da informação e o fluxo da informação (RIBEIRO; SILVA, 2000, 2004; RIBEIRO, 2005). É sobre esta última dimensão, o fluxo informacional, que incide a metodologia que segue descrita, demonstrada a partir de 3 critérios (pertinência, densidade e frequência):

Tabela 1 - Avaliação sobre o fluxo informacional

\begin{tabular}{|c|c|c|c|}
\hline & Pertinência & Densidade & Frequência \\
\hline Descrição & $\begin{array}{l}\text { Soma dos objetivos } \\
\text { essenciais + estrutura } \\
\text { orgânica e competên- } \\
\text { cias/funções + me- } \\
\text { mória }\end{array}$ & $\begin{array}{l}\text { Eliminar a dupli- } \\
\text { cidade desneces- } \\
\text { sária de informa- } \\
\text { ção, seja na cons- } \\
\text { tatação de cópias } \\
\text { exatas ou replica- } \\
\text { ção da informa- } \\
\text { ção em formatos } \\
\text { diferentes. }\end{array}$ & $\begin{array}{l}\text { Quantificação da } \\
\text { periodicidade de } \\
\text { uso/acesso à in- } \\
\text { formação }\end{array}$ \\
\hline Parâmetros & $\begin{array}{l}\text { Dividido em níveis } \\
\text { A, B, C: } \\
\text { Nível A: objetivos } \\
\text { essenciais da organi- } \\
\text { zação, constituição } \\
\text { fundacional; } \\
\text { Nível B: funções- } \\
\text { meio; } \\
\text { Nível C: atos infor- } \\
\text { macionais periféricos. }\end{array}$ & $\begin{array}{l}\text { Ato informacio- } \\
\text { nal pri- } \\
\text { mário/original } \\
\text { dispensa o seu } \\
\text { duplicado absolu- } \\
\text { tamente idêntico } \\
\text { Um ato secun- } \\
\text { dário (resumo ou } \\
\text { síntese) será subs- } \\
\text { tituível pelo pri- } \\
\text { mário, com exce- } \\
\text { ções (ex: rela- } \\
\text { tórios anuais) } \\
\text { Verificar a desa- } \\
\text { tualização da in- } \\
\text { formação }\end{array}$ & $\begin{array}{l}\text { Média padrão: } \\
52 \text { pedidos/ano; } \\
\text { Usos fra- } \\
\text { cos/mínimos: } \\
\text { inferiores a } \\
20 \\
\text { Outros quesitos a } \\
\text { serem avaliados: } \\
\text { Identificação dos } \\
\text { usuários } \\
\text { Justificação do } \\
\text { pedido } \\
\text { Ocorrência de } \\
\text { um período mui- } \\
\text { to concentrado } \\
\text { ou curto de tem- } \\
\text { po }\end{array}$ \\
\hline Ponderação & $\begin{array}{l}1 \text { (informação de } \\
\text { nível A ou B) ou } 0 \\
\text { (informação de nível } \\
\text { C) }\end{array}$ & $\begin{array}{l}1 \text { (informação } \\
\text { mais densa) ou } 0 \\
\text { (informação me- } \\
\text { nos densa) }\end{array}$ & $\begin{array}{ll}1 & \text { (uso } \\
\text { máximo/médio) } \\
\text { ou } 0 \text { (uso } \\
\text { mínimo, menos } \\
\text { de } 1 \text { vez por se- } \\
\text { mana). }\end{array}$ \\
\hline
\end{tabular}

Fonte: elaboração do autor, baseado em Ribeiro; Silva, 2000, 2004; Ribeiro, 2005 
O primeiro parâmetro expresso pelos autores, a pertinência, implica no entendimento estrutural e organizacional, distribuído nas atividades-fim (nível A), atividades-meio (nível B) e outros atos informacionais, periféricos ou redundantes (nível C).

$\mathrm{Na}$ verificação da densidade informacional, algumas questões auxiliam na definição dos parâmetros: é um documento primário/original, com/sem cópia exata ou é secundário, com/sem duplicação/cópia?

Por fim, a análise da frequência atesta o uso da informação, que, apesar de não determinar sozinha os critérios para avaliação, pode resultar no entendimento do que esta informação significa para os diferentes usuários de uma organização, entendimento justificado pelo seu caráter utilitário e por suas necessidades informacionais.

A partir desta análise ${ }^{4}$ é possivel determinar o destino da informação, se conservação permanente, conservação temporária ou eliminação, conforme tabela abaixo:

Tabela 2 - Decisão sobre o destino final da informação

\begin{tabular}{|c|c|c|c|}
\hline PERTINÊNCIA & DENSIDADE & FREQUÊNCIA & DESTINO FINAL \\
\hline Nível A & 1 & 1 ou 0 & Conservação permanente \\
\hline Nível A & 0 & 1 & Conservação temporária \\
\hline Nível A & 0 & 0 & Eliminação \\
\hline Nível B & 1 & 1 ou 0 & Conservação permanente \\
\hline Nível B & 0 & 1 & Conservação temporária \\
\hline Nível B & 0 & 0 & Eliminação \\
\hline Nível C & 1 ou 0 & 1 & Conservação temporária \\
\hline Nível C & 1 ou 0 & 0 & Eliminação \\
\hline
\end{tabular}

Fonte: Ribeiro; Silva, 2000, 2004; Ribeiro, 2005

\section{Rediscutindo o valor e avaliação da informação}

Complementando as abordagens contemporâneas supracitadas, propomos o estudo de novas perspectivas de valor e avaliação, que vão além da determinação dos prazos de guarda - prazos prescricionais e precaucionais - e da racionalização da documentação como consequência deste processo avaliativo. Abbagnano 
(2007) traz uma discussão sobre o conceito de valor, passando por diversas perspectivas filosóficas e culminando em um conceito que:

[...] considera [o valor] como possibilidade de escolha, isto é, como uma disciplina inteligente das escolhas, que pode conduzir a eliminar algumas delas ou a declará-las irracionais ou nocivas, e pode conduzir (e conduz) a privilegiar outras, ditando a sua repetição sempre que determinadas condições se verifiquem. Em outros termos, uma teoria do Valor, como crítica dos Valores, tende a determinar as autênticas possibilidades de escolha, ou seja, as escolhas que, podendo aparecer como possíveis sempre nas mesmas circunstâncias, constituem pretensão do Valor à universalidade e à permanência. (ABBAGNANO, 2007, p. 993).

Nesta compreensão mais alargada do conceito de avaliação, é preciso buscar o entendimento de como o sujeito atribui valor à informação, confere veracidade e qualidade na representação do fato, fenômeno ou objeto a ser registrado, em quaisquer suportes e plataformas. Isto implica, também, em um exercício interdisciplinar na construção de modelos avaliativos da informação.

Pretendemos trazer perspectivas complementares quanto ao valor informacional, como a dos conceitos de indício, evidência e prova (ROCKEMBACH, 2012, 2013a, 2013b, 2013c), como valores a serem atribuídos à informação, e, ainda, a Teoria dos Atos dos Documentos (SMITH, 2005), também como atribuição de valores da informação, entretanto associada à produção de efeitos sociais a partir dos documentos.

Em Rockembach (2012, 2013a, 2013b, 2013c) vemos que a informação pode apresentar aspectos de indício, evidência e/ou prova. No indício, fundamentado no método indiciário (GINZBURG, 1989, 1991), são levados em consideração pistas, sinais ou vestígios, que auxiliam na reconstrução do passado. $\mathrm{O}$ indício também possui características não-intencionais, pois estes vestígios não são produzidos com a intencionalidade comum ao registro/documento, são inferências realizadas a partir de uma análise contextual do ambiente da produção desta informação.

A evidência ${ }^{5}$, por sua vez, do latim evidentia: possibilidade de ver, clareza, de videre, ver (MORFAUX; LEFRANC, 2005, p. 214), ou ainda do “[...] verbo video: ex video é uma vidência que vem de dentro." (GIL, 1998. p. 84), 
tem relações tanto com os sentidos humanos como com a representação do que estes sentidos captam a partir da linguagem, pois "[...] o pensamento da evidência constrói-se sobre o sistema perceção-linguagem.” (GIL, 1996, p. 11).

A prova, ou o fazer probatório, nasce da necessidade de legitimação de determinada informação ou conjunto de evidências, e isto não está livre da intencionalidade do sujeito. Silva diz que a “[...] prova ou instituir prova não está imune ao efeito modelador da interpretação subjetiva [...]." (SILVA, 2006, p. 167). Esta ligação entre indício, evidência e prova pode ser demonstrada pela seguinte citação:

Quanto menos sinais/indícios são verificáveis menos evidente se torna o evento ou o objeto e mais impossibilitada ficará a construção de uma prova contundente. Evidenciar corresponde a conhecer alguma coisa (fato ou objeto), enquanto que provar liga-se ao reconhecimento desta coisa. A evidência constitui-se nas relações internas da prova, são os nós que amarram e sustentam a demonstração e legitimação da informação probatória. (ROCKEMBACH, 2012, p. 68).

O indício, a evidência e a prova possuem, respectivamente, uma natureza probabilística, informativa e normativa, não sendo opostas, mas complementares entre si. Estas relações são demonstradas na figura abaixo:

Figura 1 - Indício, evidência, prova e suas caraterísticas informacionais

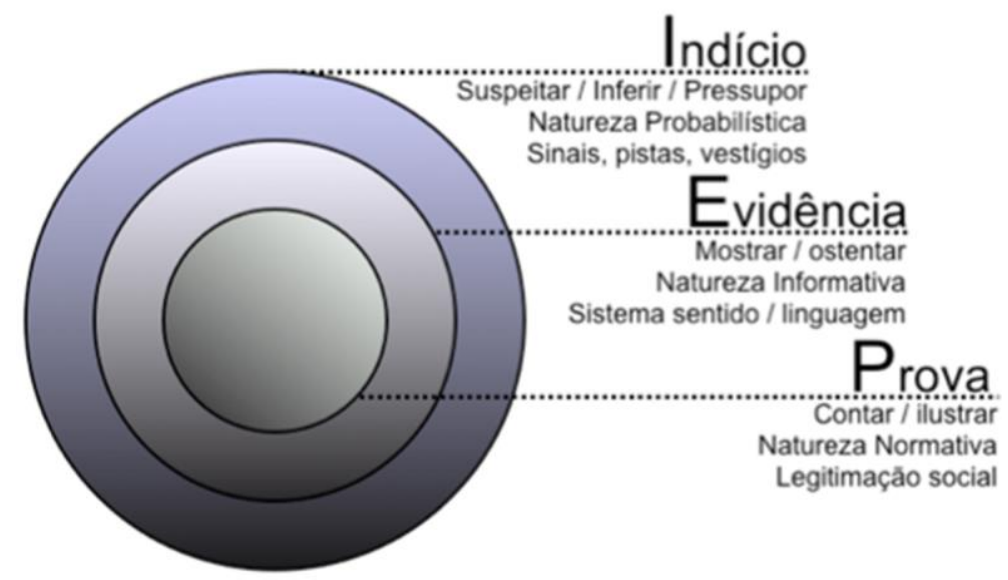

Fonte: Rockembach, 2012, p. 73

A partir deste entendimento, podemos vislumbrar um modelo que procure identificar a evidência da informação, em maior ou menor nível, questionando 
principalmente sobre: a vigilância epistêmica na produção de informações; a forma de apresentação da informação; a completude das informações; o cumprimento dos objetivos de informar; a credibilidade da autoria e, por fim, a própria forma como é organizada e recuperada a informação.

Partindo destas perguntas e de uma reflexão de Silva (2006) sobre o valor evidencial, surge um modelo de evidência da informação, onde são relacionados os elementos da evidência (variáveis) e seus respectivos indicadores:

Tabela 3 - Variáveis da evidência e seus indicadores

\begin{tabular}{|l|l|}
\hline Variáveis & Indicadores \\
\hline Tipo informacional & $\begin{array}{l}\text { Avaliar tanto as informações conforme } \\
\text { sua função, quanto à validade do seu } \\
\text { conteúdo (vigilância epistêmica) }\end{array}$ \\
\hline Contexto & $\begin{array}{l}\text { Avaliar como são apresentadas as in- } \\
\text { formações e seus componentes exter- } \\
\text { nos (que o contextualizam) }\end{array}$ \\
\hline Situação & $\begin{array}{l}\text { Avaliar se a informação possui histori- } \\
\text { cidade (data de criação/atualizações) }\end{array}$ \\
\hline Memória & $\begin{array}{l}\text { Avaliar como são organizadas e pre- } \\
\text { servadas as informações para os usos } \\
\text { da evidência (recuperação da informa- } \\
\text { ção) }\end{array}$ \\
\hline Interatividade & $\begin{array}{l}\text { Avaliar nível de interatividade propor- } \\
\text { cionado na produção e fluxos da in- } \\
\text { formação, além dos dispositivos e } \\
\text { aplicativos utilizados (mobilidade e } \\
\text { comunicação) }\end{array}$ \\
\hline Necessidade & $\begin{array}{l}\text { Avaliar se a busca da informação é } \\
\text { satisfatória (se as fontes são evidentes) }\end{array}$ \\
\hline
\end{tabular}

Fonte: Rockembach, 2013a, p. 103

Vejamos ainda uma perspectiva a partir da Teoria dos Atos dos Documentos. A abordagem inicial parte da Filosofia da Linguagem e da Teoria dos Atos da Fala, que, por sua vez, dá origem a Teoria dos Atos dos Documentos. A Filosofia da Linguagem, segundo Torres e Almeida (2014):

[...] é uma especialidade da Filosofia Analítica que tem como objeto de estudo a forma como as pessoas se comunicam. Investiga como as pessoas dizem o que querem dizer e o conteúdo da fala que pode ser constituída de perguntas, ordens, promessas, desculpas etc. Busca compreender de que forma essas emissões se relacionam com o 
mundo e como essas enunciações podem ser caracterizadas como verdadeiras, falsas, sem significação, etc.

Há uma distinção entre a Teoria dos Atos da Fala e a Teoria dos Atos dos Documentos, fundamentada principalmente na diferença entre a oralidade e a escrita. Os autores trazem esta evolução histórica, citando que "[...] o homem desenvolveu a escrita, que é provavelmente o mais perfeito e o menos obscuro sistema de linguagem visual." (MARTINS, $2002{ }^{6}$ apud TORRES; ALMEIDA, 2014), possibilitando à sociedade reter e recuperar a informação de forma mais eficaz. Esta teoria é potencializada pelo

[...] papel essencial que os documentos passaram a ter na sociedade após a passagem de uma sociedade oral para uma sociedade letrada, em função de revelarem uma variedade de poderes éticos e legais." (ALMEIDA; CENDON; KERR, $2011^{7}$ apud TORRES; ALMEIDA, 2014).

A Teoria dos atos da fala pode ser entendida como "[...] maneiras pelas quais as pessoas usam palavras e sentenças na manifestação do discurso." (SMITH, 2010 ${ }^{8}$ apud TORRES, ALMEIDA, 2014). Torres e Almeida (2014) ainda fazem referência às expressões performativas, “[as] quais não estão sujeitas à verdade ou à falsidade, mas ao sucesso ou insucesso.”. Portanto, não se pode atribuir um valor de verdade às expressões performativas, ao contrário do que acontece com as expressões constatativas, que tem por finalidade registrar ou transmitir informação direta acerca dos fatos (AUSTIN, $1990^{9}$ apud KUNZ; STUMPF, 2010).

Somado a estas categorias, Kunz e Stumpf (2010, p. 281) trazem, a partir das considerações de Benveniste (2005), uma proposta de critérios de análise das expressões performativas, subdivididas em:

a) análise do proferimento - quando o proferimento coincide com o ato, isto é, ao proferir $\mathrm{X}$, fez $\mathrm{X}$, dita em primeira pessoa;

b) análise das condições de felicidade - já que não podemos atribuir valorverdade as expressões performativas, Austin propôs condições de felicidade ou circunstâncias adequadas (AUSTIN, 1990, p.3010, apud KUNZ; STUMPF, 2010, p. 277). Nesta análise devem ser observados os seguin- 
tes quesitos: "Deve existir um procedimento convencionalmente aceito, que apresente um determinado efeito convencional e que inclua o proferimento de certas palavras, por certas pessoas, e em certas circunstâncias.", "[...] as pessoas e circunstâncias particulares, em cada caso, devem ser adequadas ao procedimento específico invocado.”, "O procedimento tem de ser executado, por todos os participantes, de modo correto e completo." (AUSTIN, 1990, p. $31^{11}$ apud KUNZ; STUMPF, 2010, p. 281);

c) critério de autoridade - critério não previsto por Austin, que Kunz e Stumpf (2010) trazem como condições de felicidade de um performativo, que “[...] só tem existência como ato de autoridade. Ora, os atos de autoridade são em primeiro lugar e sempre, enunciações proferidas por aqueles a quem pertence o direito de enunciá-los.” (BENVENISTE, 2005, p.302 $2^{12}$ apud KUNZ; STUMPF, 2010, p.281).

\begin{abstract}
Essa nova visão proposta por Austin tem como consequência o surgimento de um novo paradigma teórico, onde a linguagem é considerada como uma forma de atuação sobre o real e não mais sua representação. Há também nesse novo paradigma, a substituição do conceito de verdade (conceito central da semântica clássica) para o conceito de eficácia do ato, ou seja, as condições de sucesso e a dimensão moral do compromisso assumido na interação comunicativa. Na concepção de Austin o ato da fala tem um caráter contratual ou de compromisso entre as partes, expressa na frase: "minha palavra é meu penhor. (TORRES; ALMEIDA, 2014).
\end{abstract}

Na delimitação das funções dos documentos, podemos identificar tanto a função informativa, ou seja, o registro de informações sob um suporte, com a potencialidade de sua comunicação ${ }^{13}$, como a criação de diversos poderes institucionais e sociais, configurando-se em poderes deônticos, estes só possíveis quando gerados dentro de uma estrutura de poder (SEARLE, 1995 ${ }^{14}$ apud TORRES; ALMEIDA, 2014). Os poderes deônticos

[...] seriam responsáveis por desempenhar um papel essencial em muitas interações sociais, podendo unir pessoas, grupos ou nações (casamento, constituições federais) e criar obrigações que podem sobreviver até mesmo à morte dos autores envolvidos, como no caso de testamentos. (SEARLE, $1995^{15}$ apud TORRES; ALMEIDA, 2014). 
Smith (2005), quando elabora sua Teoria dos Atos dos Documentos, vai além dos usos informativos e probatórios dos documentos, abordando-os nas esferas ética, legal, social e institucional, desempenhando eles um papel essencial em muitas interações sociais, inseridas na complexidade da Sociedade e das Organizações contemporâneas e catalisadas por meio das Tecnologias de Informação e Comunicação.

A análise dos efeitos dos poderes deônticos a partir dos documentos pode constituir-se em um campo de estudo interessante, na medida em que se identifica, por um lado, a intenção do produtor da informação, e, por outro, os usos que se fazem desta informação, que muitas vezes podem não ser coincidentes. Smith (2005) fala que os atos da fala, em contextos locais da vida cotidiana, têm uma conexão imediata entre autor e destinatário e suas consequências deônticas são ancoradas à realidade através das memórias das pessoas envolvidas (SMITH, 2005).

A prova como argumento de veracidade pode ser feita através do que Smith chama de "conhecimento por comparação" (knowledge by comparison) em contraste com o conhecimento direto (knowledge by acquaintance) ou o conhecimento por descrição (knowledge by description), no qual ocorre, por exemplo, na presença do portador de um passaporte, a comparação da fotografia com o indivíduo ou entre a assinatura do documento e a assinatura realizada presencialmente pelo indivíduo (SMITH, 2005). Ele ainda acrescenta que,

[...] fisicamente, anexando um visto a um passaporte podemos observar vários efeitos deônticos: ele suporta a identificação do portador do visto; fornece provas de que o visto foi legalmente emitido; e garante, tanto do ponto de vista legal quanto prático, que as regras de um determinado país aplicáveis ao porte de passaportes são aplicadas automaticamente para o porte de vistos. ${ }^{16}$ (SMITH, 2005, p. $6)$.

Para fins de ilustração trazemos a figura abaixo, procurando demonstrar este percurso histórico do surgimento de metodologias de avaliação: 
Figura 2 - Metodologias de avaliação

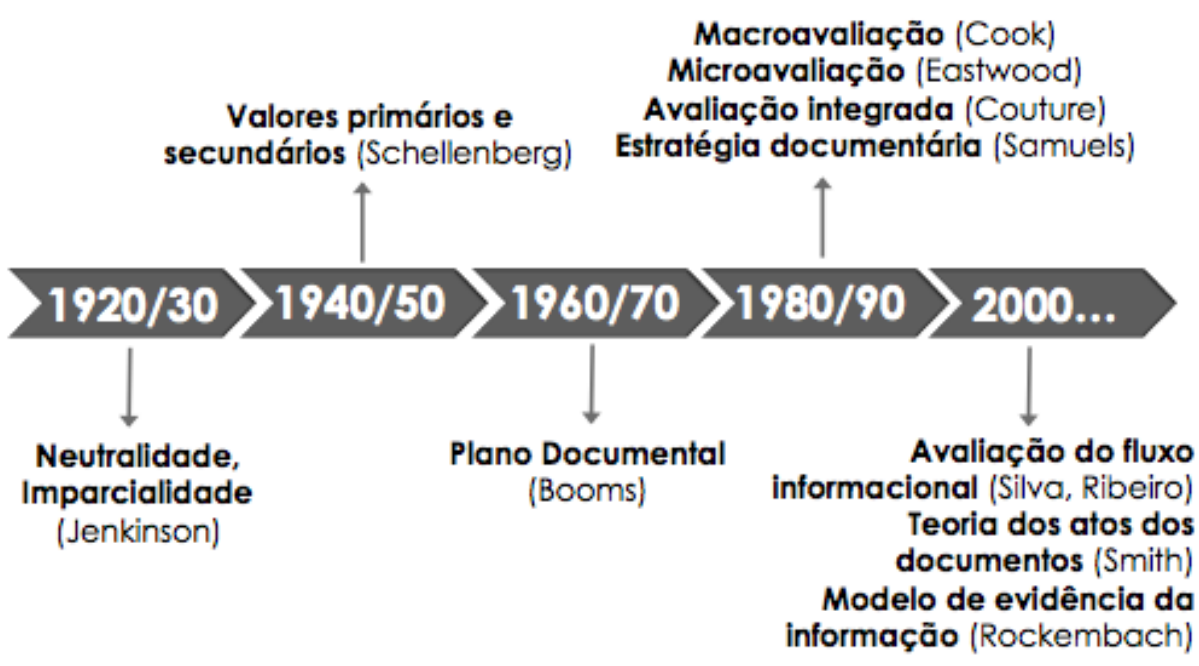

Fonte: elaboração do autor.

\section{Considerações finais}

As proposições trazidas neste estudo ainda encontram-se em desenvolvimento, mas permitem caminharmos para um melhor entendimento deste processo tão relevante que é a avaliação de documentos e informações.

As metodologias de avaliação de documentos nasceram da necessidade de racionalizar a documentação, de economia de espaço e infraestrutura essencial para armazenar o crescimento constante dos arquivos. As metodologias clássicas de avaliação, sobretudo de Schellenberg e alguns dos seus contemporâneos, tinham este objetivo, manter o máximo da informação com o mínimo da documentação.

Entretanto, num mundo com organizações cada vez mais complexas, onde as informações são produzidas em diversos meios e contextos, uma visão pós-moderna, consoante a uma sociedade pós-moderna, pode auxiliar no amadurecimento de discussões terminológicas sobre valor e metodologias avaliativas. E, além disto, pensar na avaliação não só como um processo de gestão, mas como uma construção epistêmica. São proposições, enfim, que podem nos levar a um profícuo debate interdisciplinar e à ligação de saberes diversos, porém convergentes. 


\section{Referências}

ABBAGNANO, Nicola. Dicionário de filosofia. 5 ed. São Paulo: Martins Fontes Editora, 2007.

AUSTIN, John Langshaw. Quando dizer é fazer: palavras e ação. Porto Alegre: Artes Médicas, 1990.

BENVENISTE, Emile. A filosofia analítica e a linguagem. In: BENVENISTE, Emile. Problemas de lingüística geral I. 5. ed. Campinas: Pontes, 2005.

BRUYNE, Paul de; HERMAN, Jacques e SCHOUTHEETE, Marc de. Dinâmica da pesquisa em ciências sociais: os pólos da prática metodológica. Rio de Janeiro: Francisco Alves, 1977

COOK, Terry. Macroappraisal in theory and practice: origins, characteristics, and implementation in canada, 1950-2000 Archival Science, Heidelberg, n.5, p.101-161, 2005.

CUNNINGHAM, Adrian; OSWALD, Robyn. Some Functions are More Equal than Others: The Development of a Macroappraisal Strategy for the National Archives of Australia. Archival Science, Heidelberg, v. 5, n. 2, p. 163-184, 2005.

GIL, Fernando. Tratado da evidência. Lisboa: Imprensa Nacional Casa da Moeda, 1996.

GIL, Fernando. Modos da evidência. Lisboa: Imprensa Nacional Casa da Moeda, 1998.

GINZBURG, Carlo. Mitos, emblemas, sinais: morfologia e historia. São Paulo: Companhia das Letras, 1989.

GINZBURG, Carlo. Chaves do mistério: Morelli, Freud e Sherlock Holmes. In: ECO, Umberto; SEBEOK, Thomas (Org.) O signo de três. São Paulo: Perspectiva, 1991. p. 90-129

JENKINSON, Hilary. A manual of archive administration. London: Percy Lund, Humphries and Co., 1922.

KUNZ, Júlio César; STUMPF, Elisa Marchioro. Constatativos e performativos: Austin e Benveniste sobre os atos de fala. In: SEMINÁRIO INTERNACIONAL DE TEXTO, ENUNCIACCÃO E DISCURSO, 2010, Porto Alegre. Anais do SITED - Seminário Internacional de Texto, Enunciação e Discurso. Porto Alegre: Pontifícia Universidade Católica do Rio Grande do Sul, 2010.

Disponível em <http://ebooks.pucrs.br/edipucrs/anais/sited/arquivos/JulioCesarKunzeElisaMar chioroStumpf.pdf>. Acesso em: 7 set. 2015. 
MAKHLOUF, Basma; CAVALCANTE, Lídia Eugenia. Avaliação Arquivística: Bases teóricas, estratégias de Aplicação e instrumentação. Encontros Bibli, Florianópolis, v. 13, n. 26, p. 201-213, 2008.

MORFAUX, Louis-Marie; LEFRANC, Jean. Novo dicionário da filosofia e das ciências humanas. Lisboa: Instituto Piaget, 2005.

MULLER, Samuel; FEITH, Johan; FRUIN, Robert. Manual de arranjo e descrição de arquivos.. Rio de Janeiro: Arquivo Nacional, 1973. Disponível em <http://www.portalan.arquivonacional.gov.br/media/manual_dos_arquivistas.pd f >. Acesso em: 26 jul. 2015

RIBEIRO, Fernanda; SILVA, Armando Malheiro da. A avaliação em arquivística: reformulação teórico-prática de uma operação metodológica. Lisboa: Páginas A\&B, 2000.

RIBEIRO, Fernanda; SILVA, Armando Malheiro da. A avaliação de informação: uma operação metodológica. Lisboa: Páginas A\&B, 2004.

RIBEIRO, Fernanda. Novos caminhos da avaliação de informação. Arquivística net., Rio de Janeiro, v. 1, n. 2, jul./dez. 2005.

ROCKEMBACH, Moisés. Modelo de evidência da informação em plataformas digitais: estudo exploratório no âmbito da Ciência da Informação. 2012. Tese (Doutorado em Informação e Comunicação em Plataformas Digitais) - Universidade do Porto / Universidade de Aveiro, Porto, 2012.

ROCKEMBACH, Moisés. Evidência da informação em plataformas digitais: da reflexão teórica à construção de um modelo. Informação Arquivística, Rio de Janeiro, v. 2, p. 89-109, 2013a.

ROCKEMBACH, Moisés. Información evidencial en entornos Digitales. In: CÁRDENAS ZARDONI, Horacio Enrique (Org.) Entorno digital y futuro de la cultura. Cáceres: Fundación Ciencias de la Documentación, 2013b.

ROCKEMBACH, Moisés. New approaches to information quality in the digital environment: clues, evidence, and proof. In: JAMIL, George; SILVA, Armando Malheiro da; RIBEIRO, Fernanda. Rethinking the conceptual base for new practical applications in information value and quality. Hershey: IGI Global, 2013c.

ROUSSEAU, Jean-Yves; COUTURE, Carol. Os fundamentos da disciplina arquivística. Lisboa: Publicações Dom Quixote, 1998.

SCHELLENBERG, Theodore Roosevelt. Modern Archives: principles and techniques. Chicago: The Society of American Archivists, 2003. Disponível em: 
<http://www.archivists.org/publications/epubs/ModernArchives-

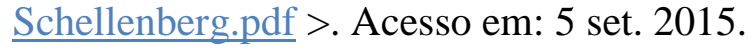

SEARLE, John. The construction of social reality. New York: Free Press, 1995.

SILVA, Armando Malheiro da et al. Arquivística: teoria e prática de uma ciência da informação. Porto: Afrontamento, 1998.

SILVA, Armando Malheiro da. A informação: da compreensão do fenómeno e construção do objecto científico. Porto: Afrontamento, 2006.

SMITH, Barry. Document acts. 2005. Notas da conferência apresentada no Ontolog Forum em outubro de 2005. Disponível em:

〈http://ontology.buffalo.edu/document_ontology/document_acts.doc〉. Acesso em: 8 jul. 2015.

TSCHAN, Reto. A comparison of Jenkinson and Schellenberg on appraisal. The American Archivist, Chicago, v. 65, n. 2, p. 176-195, 2002.

TORRES, Simone; ALMEIDA, Maurício B. Reflexões sobre a função social do documento aplicadas à documentação jurídica. DataGramaZero, Rio de Janeiro, v.15, n.2, abr. 2014. Disponível em <http://www.dgz.org.br/abr14/F_I_art.htm>. Acesso em: 04 jul. 2015

\title{
Concepts, models and new perspectives on the appraisal in Ar- chival Science and Information Science
}

\begin{abstract}
This paper presents the process of appraisal of information starting from an analysis of the methods proposed by different authors in the fields of Archival Science and Information Science. The study starts from a classical perspective of appraisal, with Jenkinson (1922) and Schellenberg (2003) and their Theory of Values; going through a postmodern approach of macroappraisal, proposed by Terry Cook (2005), who criticizes the previous model and proposes a systematic and holistic approach to the process; through interdisciplinarity within Information Science, studied by Silva and Ribeiro (2000, 2004); and Ri-
\end{abstract}


beiro (2005) and his studies of information flows. Complementary perspectives of the value of information are proposed, with the concepts of clue, evidence and proof (Rockembach 2012, 2013a, 2013b, 2013c), as well as the Theory of the Documents Acts (Smith, 2005). The study concludes that the interdisciplinary debate may be of great importance for the terminological and methodological construction of appraisal.

Keywords: Appraisal of information. Evaluation models. Archival science. Information science.

Recebido em 19/10/2015

Aceito em: 20/12/2015

${ }^{1}$ Projeto de pesquisa "Valor e avaliação em Arquivologia: contextualização histórica conceitos, teorias e novas perspectivas", em desenvolvimento na Universidade Federal do Rio Grande do Sul (UFRGS) / Faculdade de Biblioteconomia e Comunicação (FABICO), Porto Alegre, Brasil.

${ }^{2}$ No original: "[...] primary values for the originating agency itself and secondary values for other agencies and private users [...].".

${ }^{3}$ No original: "Schellenberg had long believed in the limited applicability of European archival practice to the realities of modern records production in the United States, and his text was generally accepted as an exposition of the new manner in which archives should be administered.".

${ }^{4}$ A explicação da metodologia de avaliação do fluxo informacional e as tabelas trazidas neste artigo não dispensam a leitura dos artigos originais (Ribeiro; Silva, 2000, 2004; Ribeiro, 2005), que explicam de maneira mais pormenorizada os critérios e parâmetros envolvidos.

${ }^{5}$ Uma abordagem que analisa a evidência da informação em plataformas digitais pode ser vista em Modelo de evidência da informação em plataformas digitais: estudo exploratório no âmbito da ciência da informação (ROCKEMBACH, 2012), Evidência da Informação em plataformas digitais: da reflexão teórica à construção de um modelo (ROCKEMBACH, 2013a), Información Evidencial en Entornos Digitales (ROCKEMBACH, 2013b) e New Approaches to Information Quality in the Digital Environment: Clues, Evidence, and Proof (ROCKEMBACH, 2013c).

${ }^{6}$ MARTINS, Wilson. A palavra escrita: história do livro, da imprensa e da biblioteca. 3. ed. São Paulo: Ática, 2002.

${ }^{7}$ ALMEIDA, Maurício Barcellos; CENDON, M.B.; KEER, M. P. Princípios metodológicos para a caracterização da dimensão pragmática de documentos no desenvolvimento de ontologias biomédicas. Belo Horizonte: [S.n.], 2011.

${ }^{8}$ Smith, Barry. Document acts. [S.1.], [2005]. Disponível em: <http://ontology.buffalo.edu/document_ontology/document_acts.doc〉. Acesso em: 4 jul. 2015.

${ }^{9}$ AUSTIN, J. Quando dizer é fazer. Porto Alegre: Artes médicas, 1990.

${ }^{10}$ AUSTIN, J. Quando dizer é fazer. Porto Alegre: Artes médicas, 1990.

${ }^{11}$ AUSTIN, J. Quando dizer é fazer. Porto Alegre: Artes médicas, 1990.

${ }^{12}$ BENVENISTE, E. A filosofia analítica e a linguagem. In: BENVENISTE, E. Problemas de lingüística geral I. 5. ed. Campinas: Pontes, 2005.

${ }^{13}$ Ver fenômeno info-comunicacional, conforme Silva (2006).

${ }^{14}$ SEARLE, J. The construction of social reality. New York: Free Press, 1995.

${ }^{15}$ SEARLE, J. The construction of social reality. New York: Free Press, 1995.

${ }^{16}$ No original: "Physically attaching a visa to a passport can in this way have multiple deontic effects: it supports identification of the bearer of the visa; provides evidence that the visa was both legally issued and issued to the person presenting it; and ensures, from both a legal and a practical point of view, that 
Conceitos, modelos e novas perspectivas de avaliação em Arquivologia e Ciência da informação Moisés Rockembach

the rules in a given country applying to the carrying of passports are applied automatically to the carrying of visas.". 